\title{
A Mobile Application Design to Prevent Criminal Acts in Lima, Peru
}

\author{
Alexi Delgado ${ }^{*},{ }_{\text {, Enrique Lee Huamaní }}{ }^{\text {, Elizabeth Jenny Cortez-De La Peña }}{ }^{2}$ \\ ${ }^{1}$ Mining Engineering Section, Pontificia Universidad Católica del Perú, 15088, Peru \\ ${ }^{2}$ Systems Engineering Program, Universidad de Ciencias y Humanidades, 15307, Peru
}

\begin{tabular}{l} 
A R T I C L E I N F O \\
\hline Article history: \\
Received: 25 March, 2020 \\
Accepted: 14 June, 2020 \\
Online: 06 July, 2020
\end{tabular}

Keywords:

Balsamiq Wireframes

Design

Mobile Application

\begin{abstract}
A B S T R A C T
In the province of Lima, Peru, criminal acts are increasing every day; it is a social problem that affects many people, who often try with the life of the indignant person, becoming the greatest fear of the community. For this reason, a mobile application was designed that allows the inhabitants to report and share the criminal acts that occur in their environment in real time, allowing them to prevent such acts. This application was designed using the Balsamiq tool, which allows each sketch to be developed in an organized manner. The result was the development of each module that addresses each of the functionalities of the application design for its correct structuring with the Balsamiq tool. These results will help the inhabitants of Lima, Peru, to expose the facts of which they are victims, without the immediate need to go to the police station, and which will be proposed for development to different competition funds.
\end{abstract}

\section{Introduction}

Today, the area of criminality contains many criminal problems that constantly affect people's lives. Globally, the list of crimes is expanding dramatically every day [1]. In Peru, it has become a problem that, along with corruption, affects the lives of the population in about $40.4 \%$ of cases, making it the country's main problem, followed by poverty with $38.9 \%$ [2]. Thus, a safe environment has become a major public and social concern. Therefore, and taking into consideration that the purpose of engineering is to reduce human efforts and make life more comfortable in order to overcome the obstacles that arise [3], a contribution to this social problem will be sought by designing an application that is useful for the citizens of the province of Lima, Perú.

Several methodologies were found for the design of a mobile application, the first of them is the tool Justin mind platform for sharing and evaluating prototypes of web applications, iOS and Android [4]. It contains an intuitive and dynamic interface, has access to indicate actions on each element of the design and has both free and paid versions. Additionally, there is Proto.io that allows applying screen transitions and defining touch events for each design element on the screen. That creates a high-quality prototype. The prototypes can be viewed and experienced interactively within the browser, but most importantly they can be

\footnotetext{
*Alexi Delgado, Email: kdelgadov@pucp.edu.pe
}

launched on the actual mobile device [5]. Finally, there is the Balsamiq tool, the most popular being helpful for fast model building [6], it develops easily interactive models and quickly, they can be used to verify the key ideas behind an application fulfilling the user's objective [7]. Therefore, Balsamiq was chosen for the development of the design since it is useful to communicate ideas [8], speeding up the creation of sketches and schemes in a simple way. The reason for using the Balsamiq tool has been due to the experience gained in its use with respect to the prototyping of projects related to the development of mobile and web applications in addition to having the paid version that provides a wide selection of basic elements along with navigation elements, video and image areas, forms and many other functions, this tool allows you to move around the design surface simply by dragging and dropping, thus creating the wireframe.

This article uses the design of a mobile application to analyze crime in the province of Lima, which is useful for evaluating the increase or decrease of criminal acts [9], information that could be made available police officers. The application allows the affected areas to be displayed on the map and is useful for alerting and preventing citizens. It also includes a search and database of reports and data from the nearest police stations.

The objective of this investigation is to design a mobile application that allows citizens to report and share criminal acts that have occurred and, in this way, contribute to the authorities 


\section{A. Delgado et al. / Advances in Science, Technology and Engineering Systems Journal Vol. 5, No. 4, 40-46 (2020)}

taking precise actions, as well as alerting citizens who may be in the area.

The present work is constituted in the following way: section II explains the methodology by means of stages, detailing the tool used. Section III introduces the application developed sequentially showing the interfaces. Section IV shows the results obtained and the development of the discussion. Finally, section V presents the conclusions.

\section{Methods}

This research will present the design of a mobile application, to structure, simulate and make the visually friendly prototypes for the planning of the mobile development environment, to develop the application work is deployed in phases corresponding to the creation of the design.

\subsection{Creation of Users}

The mobile application has the well-known "User Stories", which allow a set of tasks to be performed, and have different accesses, permissions and privileges according to the user's functions.

\subsection{Initial Screen Design}

When the design phase of the project starts, the first and fundamental step is to represent the layout development of the mobile application, the main view; in this case a suitable tool was selected for its design: Balsamiq Mockups, which is a medium fidelity prototyping software, which allows the elaboration of functional interfaces and gives the user an initial impression of the application's operation [10]. Following this, the creation of schematics was outlined in order to speed up the design phase with functionalities represented in static form. It is worth highlighting the usefulness of this tool in this stage, since it facilitates the creation of instantaneous, polished, precise sketches to design accessible and organized tests; in other words, it has the purpose of showing the idea of the final project.

\subsection{Elaboration of the modules}

Essentially, in this phase the modeling of diverse designs within each module is produced. The general view includes the modules that provide a global appreciation that should captivate the user at first sight, contains all the functionalities by means of buttons and is intended to be direct. It is crucial to define the modules that the application will contain, because it allows the user to perform several functions that can be adapted to the development.

The application is composed of three parts as shown in Figure 1 , where the user can report and/or search for types of criminal acts, as well as communication management, where the user can observe the news section and Home module, where the user has access to his personal account.

Eventually in every mobile application modifications and variations can be presented, it is possible to improve the structure that was thought, being able to verify certain deficiencies quickly and to add interaction to the draft.

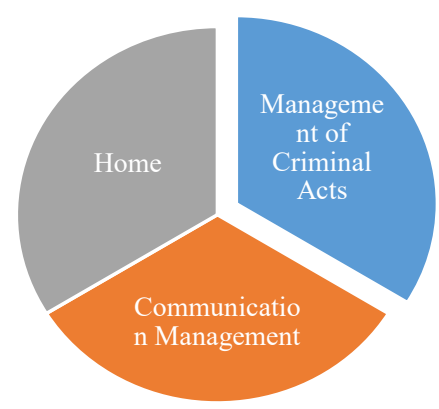

Figure 1: Mobile Application Screen Diagrams

\subsection{Implementing Mockups}

In the last phase, the project will use the Android operating system, which has developed in a major role to this eco system known as Consumer [11], Android Studio is the official environment for the development of applications in Android, written in Java language. Application Programming Interface (API) can be provided through the help of GPS technology and map manipulation using Google Maps API tools in Android [12]. Some features used are camera, microphone, map and Internet access. SQLite directly calls the corresponding API functions to perform data access operations [13].

Table 1: Functions of each user

\begin{tabular}{|c|l|}
\hline User & \multicolumn{1}{|c|}{ Function } \\
\hline Administrator & $\begin{array}{l}\text { Process of managing and controlling all } \\
\text { the functions and confidential information } \\
\text { of users, observe the reports filtered by } \\
\text { police station, type of crime, map of } \\
\text { affected areas, and can add modules with } \\
\text { new functions if needed. }\end{array}$ \\
\hline Citizen & $\begin{array}{l}\text { Access the mobile application that will be } \\
\text { validated by the administrator user for } \\
\text { registration in order to have a correct user } \\
\text { identification and avoid fraud when } \\
\text { reporting an incident. In the application } \\
\text { you can send and share criminal events } \\
\text { that occur or happen to around you and } \\
\text { even broadcast live, view a search engine } \\
\text { by incident type, view the news section } \\
\text { and map the affected areas. }\end{array}$ \\
\hline Police officers & $\begin{array}{l}\text { Receives all notifications from citizens } \\
\text { with their corresponding data (type of } \\
\text { incident, place of the event, description, } \\
\text { date, evidence, etc.) with the aim of taking } \\
\text { the corresponding measures in the } \\
\text { shortest possible time. } \\
\text { When the police accept the confirmation, } \\
\text { a notification will be sent to the citizen } \\
\text { indicating that they are going to the place } \\
\text { of the incident. }\end{array}$ \\
\hline
\end{tabular}




\section{Case Study}

\subsection{Creation of Users}

It has been considered pertinent to take into account three basic specific users, of which the functions of each user are shown in Table 1.

\subsection{Initial Screen Design}

In this phase of the design, we proceed to show the main view, the initial sketches to be taken into account for the mobile application, made with the Balsamiq tool.

When entering the application a screen is accessed directly, if the user is not in an active session, the application asks for a login either by Facebook or Google or by a user already created, as shown in Figure 2(a), likewise the option to register by filling in your personal information in the system, in case you do not have a user created, as shown in Figure 2(b).
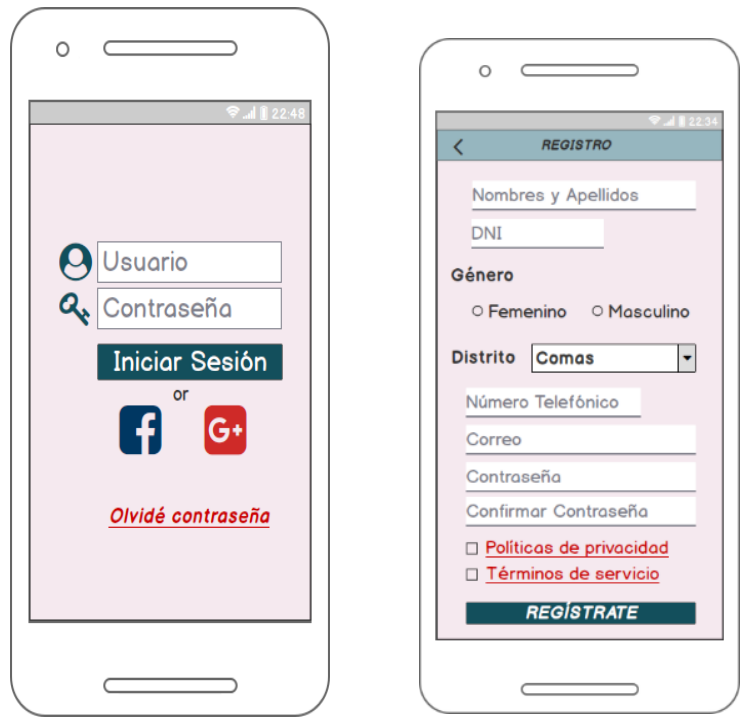

Figure 2: (a) Login Prototype, (b) Registration Prototype

Table 2: Composition of the Modules

\begin{tabular}{|c|l|}
\hline General Module & \multicolumn{1}{|c|}{ Second Level Module } \\
\hline Management of Criminal Acts & $\begin{array}{l}\text { Searching for Criminal Acts } \\
\text { Types of Criminal Events } \\
\text { Map of concerned areas } \\
\text { Report Criminal Activity }\end{array}$ \\
\hline Communication Management & $\begin{array}{l}\text { Live broadcast } \\
\text { Contacts } \\
\text { Commissaries }\end{array}$ \\
\hline Home & $\begin{array}{l}\text { News } \\
\text { History of Reports }\end{array}$ \\
\hline
\end{tabular}

\subsection{Elaboration of the modules}

The general module is shown in Table 2, with ten buttons that direct to each of the functionalities or instances of the mobile application.

\subsubsection{Criminal Management Module:}

This module consists of four instances.

a) Search for Criminal Acts: The user can filter by type of criminal act, police station, date and area to find out about the reports presented, as shown in Figure 3.

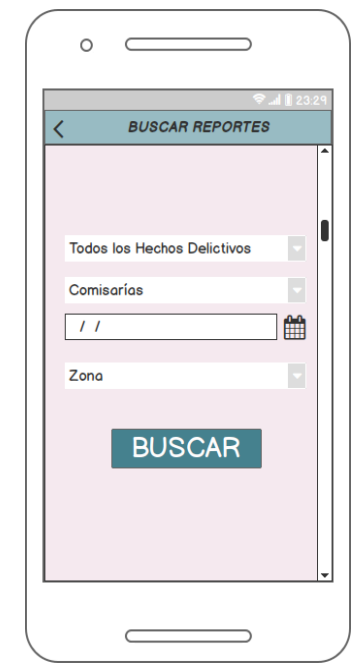

Figure 3: Search for Criminal Acts

b) Types of criminal events: The user can observe a classification of the different criminal acts that exist, this is represented in Figure 4.

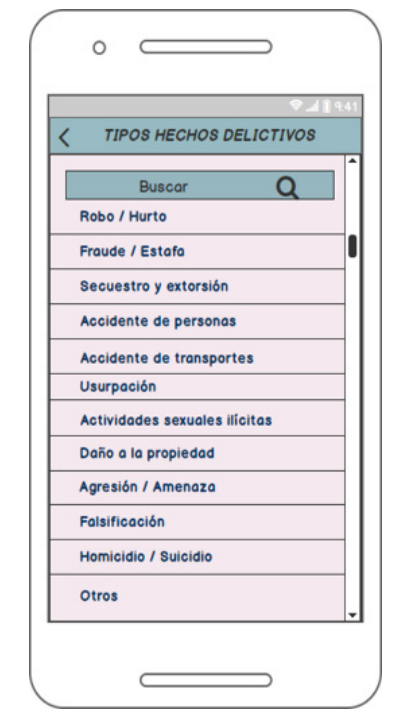

Figure 4: Types of Criminal Events

c) Map of concerned areas: This is a Google Maps map which indicates the offended areas.

d) Report of criminal activity: The contribution of the user is presented on the report (type, place, description, date, time) where it is possible to add text, 


\section{A. Delgado et al. / Advances in Science, Technology and Engineering Systems Journal Vol. 5, No. 4, 40-46 (2020)}

attach photo, video, audio and location that objectively support the affected incident.

\subsubsection{Communication Management Module: The module} contains four instances.

a) News: This section shows the publications made by the users; it has the option to comment, share and view the details.

b) Live transmission: It allows to transmit a live video sharing some criminal event in real time.

c) Contacts: The user can determine which will be the emergency contacts and have direct access to them if needed.

d) Commissaries: In this section you can see all the commissaries with their respective information as an addition, it contains a search engine for greater access.

\subsubsection{Start Module: The module is contained by two instances.}

a) Profile: In this section the information of the user is shown giving the opportunity to access to the edition of their information if needed.

b) History of reports: Screen in which the user visualizes his reports with its respective information.

\subsection{Implementation of Mockups}

To complete the design development, it will be implemented, in the future, in the Android Studio program which contains a wide range of views that can be used to develop an application containing lists, grids, text boxes, buttons and also an embedded web browser [14]. This mobile application is set up to publish, collaborate and report crime information, building a crime information map, as well as providing the opportunity for immediate assistance in emergency situations and pre-existing events, using Google libraries. The user functions are shown in Table 3.

Table 3: Characteristics

\begin{tabular}{|c|l|}
\hline Function & \multicolumn{1}{c|}{ Description } \\
\hline Localization & $\begin{array}{l}\text { The user allows the interface to recognize their } \\
\text { location when making a report. This option is } \\
\text { also imperative when searching for affected } \\
\text { areas and when sending alerts to different } \\
\text { police stations and users. }\end{array}$ \\
\hline $\begin{array}{c}\text { Photo and } \\
\text { Video }\end{array}$ & $\begin{array}{l}\text { The user can attach any photo or video of the } \\
\text { act that serves as evidence for the complaint, } \\
\text { as well as so that other users can recognize } \\
\text { those involved in a more optimal way. }\end{array}$ \\
\hline Audio & $\begin{array}{l}\text { The user can add voice audio as a sample if } \\
\text { required. }\end{array}$ \\
\hline
\end{tabular}

Figure 5(a) shows the prototype of how the interface that shows the location of the user will display; Figure 5(b) will show the areas where recent complaints have been made so that users in the environment have more information to take appropriate action.
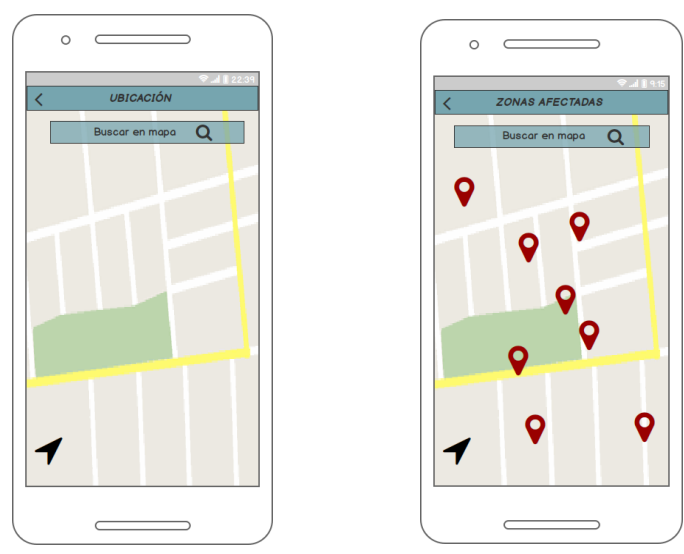

Figure 5: (a) Localization, (b) Concerned areas

The Google APIs will be used to obtain the location with the GPS network and another one to show the affected areas on a map to the user. These services are used to obtain the longitude and latitude of the reported location [15]. Records in the SQLite database are updated and uploaded to the cloud each time the user modifies any corresponding data [16]. Figure 6 shows the design that was developed to report criminal acts in order to provide citizens with a tool to validate their report, which records the type of incident, the place where it occurred, the date and time, also allows the user to add more details if desired, allowing them to publish anonymously for greater security if deemed appropriate, this anonymous information can be seen by police officers and the administrator with the limitation of not knowing which user has registered the criminal acts. Finally, in the application there will be previously detailed options to attach photo, video or share live video which will make the mobile application interactive and easy to use.

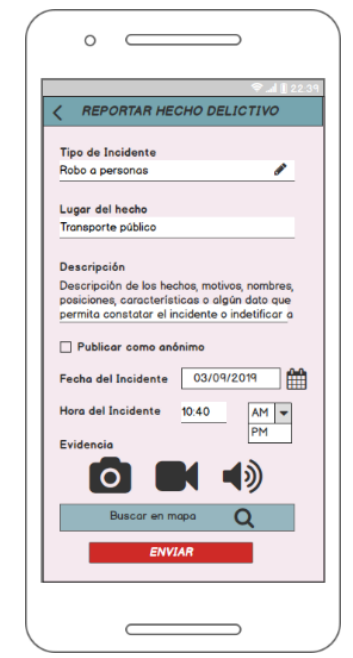

Figure 6: Criminal Act Report

\subsection{Transfer of prototypes to Android Studio}

In order to transfer all the prototypes to Android Studio for the development of the application will have to follow in the 
structure of the layout where we must open the Android Studio and create a project with the name of the application in this case we are calling "Mobile application to prevent criminal acts" and hit the Next button as shown in Figure 7.

20 Create New Project

\section{Create Android Project}

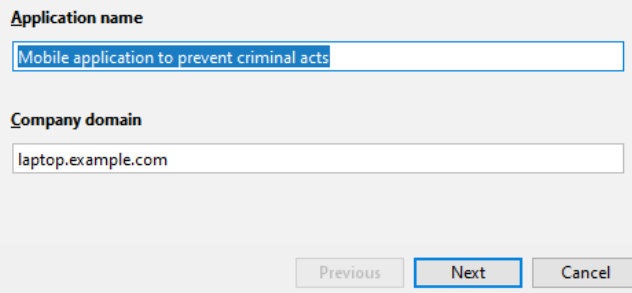

Figure 7: Project Creation in Android Studio

Then select a version of our application is recommended to use Nougat because it is currently the most stable version and give the next button as shown in Figure 8.

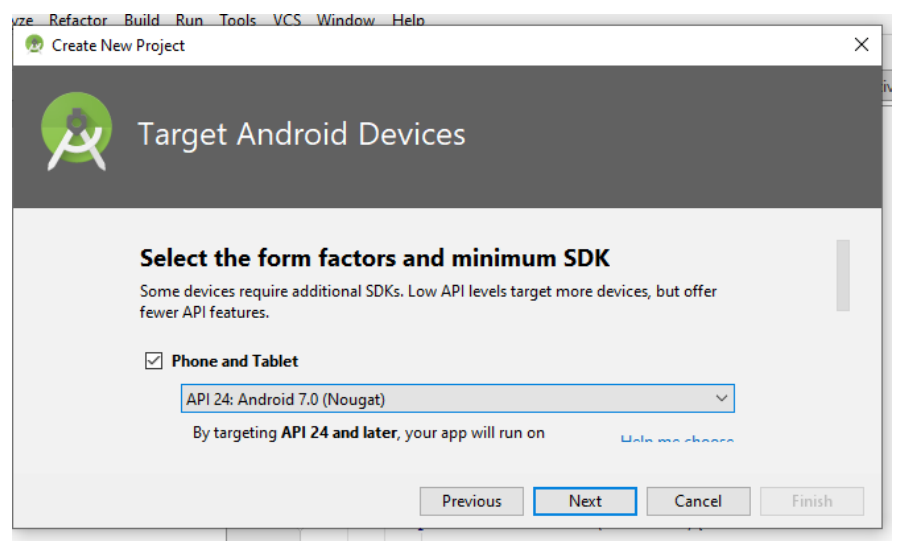

Figure 8: SDK version selection

To make it a worked from scratch application a blank template will be used as shown in Figure 9.

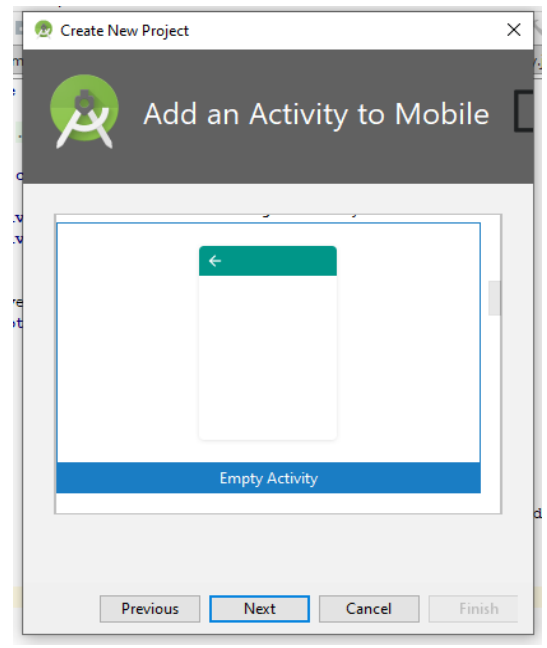

Figure 9: Empy Activity selection
Then we must create an initial project with the name MainActivity to finally give the Finish button as shown in Figure 10.

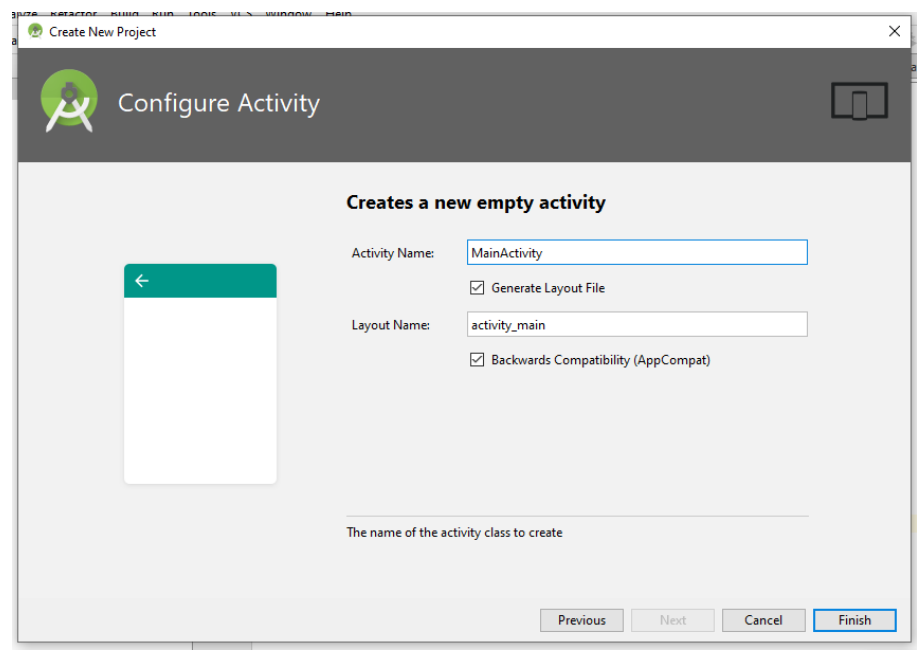

Figure 10: Completion of project creation

For the graphic development we must access the MainActivity.xml where we will have to structure the forms with respect to the model, as shown in figure 11 that was developed following the structure of the model in figure 6 .

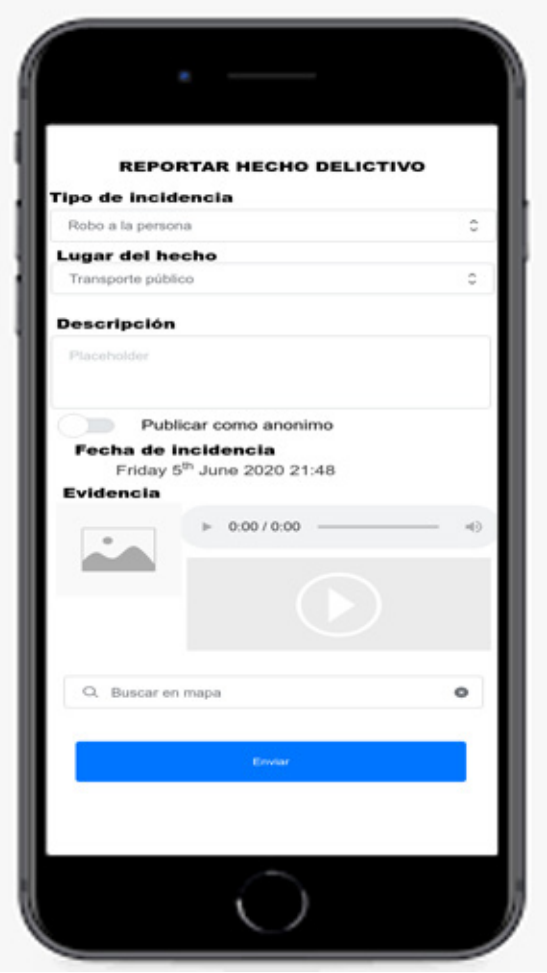

Figure 11: Transfer of prototype to Android Studio

\section{Results and Discussion}

As a result of this research we can indicate that it has contributed to propose a solution for one of the cities with the highest percentage of crime as it is the city of Lima, the proposal of this research is very important because currently there are funds 
available to compete for the implementation of mobile applications that improve the security of citizens, in Table 4 with respect to the research [2] that was mentioned in the introduction section we can validate that there is a higher percentage of crimes in Lima itself being necessary these types of proposals that can help reduce these types of incidence.

Table 4: Regions with the highest crime rate

\begin{tabular}{|c|c|}
\hline Region & Percentage \\
\hline Puno & $37.4 \%$ \\
\hline Huancavelica & $37.8 \%$ \\
\hline Callao & $38.9 \%$ \\
\hline Ayacucho & $26.9 \%$ \\
\hline Loreto & $30.2 \%$ \\
\hline Lima Metropolitana & $40.4 \%$ \\
\hline
\end{tabular}

Since in Peru we have a large number of regions, the 6 with the highest crime rate were placed with respect to Table 4 with respect to 2018, where the percentage is considered by the number of people in their region, therefore contributing with a proposal for Metropolitan Lima it could help reduce the percentage.

\subsection{About the Case Study}

As a case study, the design of the mobile application has been carried out with special dedication and in the most appropriate way, achieving a series of stages and instantaneous functionalities for its creation and correct structuring by means of the Balsamiq Mockups tool. This research tries to propose an application for the benefit of society as proposed by the research of [17] that makes a prototype proposal for a mobile application in order to reduce pollution in Peru. The prototype development serves as a basis to have a general concept of what is proposed to be done, as we can also see in the Figures with respect to the prototype a user-friendly environment, this can be modified when it is taken to the development of the application depending on the requirements that are requested.

\subsection{About the Methodology}

In Balsamiq Mockups, mobile applications are designed in a more intelligent and easy way [18], they are also used to design the structure, hierarchy and relationship between the elements that compose the mobile application [19]. Future integration will be done with Android Studio IDE, and there are several methods to make a mobile application. For this purpose, the prototype work of the Mobile Application for pneumonia management obtained in the community [20] has been observed, which had a system written in the Objective-C language using a development approach called Model View Controller (MVC); which turns out to be an interesting proposal for the proposed future objective, to also be coupled in the iOS system, as it has been evaluated in the mentioned research.

\section{Conclusion}

In this paper we managed to design the prototype of the mobile application with the Balsamiq tool showing the digital outlines of all the application modules, helping to reach a better solution to the situations of the role of the user, a design that allows the community to report any crime by attaching different evidence (such as audio, photo and/or video) and even broadcast live, also accessing the location (after activating the GPS).

The method applied was the most deductive, seeking to encompass the characteristics of the design and for this purpose the Balsamiq tool was used to contribute to the design of the application and its components defined in their respective sketches, giving a series of special features to generate interactive drawings to the benefit of end users, ensuring that the development is not compromised or slowed down at any stage.

It is recommended in future investigations to validate this design to a concrete application integrated with the National Registry of Identification and Marital Status (RENIEC by its Spanish acronym) to authenticate the data of the citizen, complementing it with topics of satellite tracking or tracing, interconnected in real time with the police stations in order to enable the immediate arrival of police and security personnel to the place of the event, and to contemplate its operation with Android Studio.

With respect to the design of the mobile application explained in this research, this proposal will be submitted to competitive seed funds such as Fondo Nacional de Desarrollo Científico y Tecnológico (Fondecyt) and the National Innovation Program for Competitiveness and Productivity (Innóvate Perú) so that it can be developed and used by citizens. This research can be improved in the visual and functional part thanks to the direct communication that would be had with the citizens when this proposal is launched.

\section{References}

[1] C. Guevara, D. Bonilla, J. Pozo, R. Pérez, H. Arias, and L. Martinez, "Mobile geographic information system for citizen security", in Iberian Conference on Information Systems and Technologies, CISTI, 2019-June, 2019. https://doi.org/10.23919/CISTI.2019.8760713

[2] C. M. Soto et al., "PLAN NACIONAL DE SEGURIDAD CIUDADANA 2019-2023" (report in Spanish), 2018.

[3] S. Bhattacherjee and G. C. Somashekhar, "Artificial intelligence to impart surveillance, tracking, \& actuation on suspicious activities", in Proceedings 7th IEEE International Advanced Computing Conference, IACC 2017, 1-5, 2017. https://doi.org/10.1109/IACC.2017.0016

[4] W. T. Mok, R. Sing, X. Jiang, and S. L. See, "Proposal of a depression detector", in 2014 Asia-Pacific Signal and Information Processing Association Annual Summit and Conference, APSIPA 2014, 2014. https://doi.org/10.1109/APSIPA.2014.7041742

[5] "Proto.io: precios, funciones y opiniones | GetApp". [Online]. Available in: https://www.getaes/software/90497/proto-dot-io. [Acceded: 03-jan-2020].

[6] J. M. Rivero, G. Rossi, J. Grigera, E. Robles Luna, and A. Navarro, "From interface mockups to Web application models", in Lecture Notes in Computer Science (including subseries Lecture Notes in Artificial Intelligence and Lecture Notes in Bioinformatics), 6997 LNCS, 257-264, 2011. https://doi.org/10.1007/978-3-642-24434-6_20

[7] S. N. Fazelah, M. Noor, Z. A. Kadir, B. Pahat, and J. Malaysia, "Students' Learning Preferences of English for Academic Purposes-A KUiTTHO Affair". Available in https://www.academia.edu/3608107/Students_Learning_Preferences_of_En glish_for_Academic_Purposes_-_A_KUiTTHO_Affair

[8] I. Bouchrika, L. Ait-Oubelli, A. Rabir, and $\bar{N}$. Harrathi, "Mockup-based navigational diagram for the development of interactive web applications", in ACM International Conference Proceeding Series, 27-32, 2013. https://doi.org/10.1145/2503859.2503864

[9] W. Chi and X. Wang, "Design of criminal analysis system based on OLAP", in ICCSE 2012 - Proceedings of 2012 7th International Conference on Computer Science and Education, 838-841, 2012. https://doi.org/10.1109/ICCSE.2012.6295200

[10] D. S. Alves, E. M. A. Da Silva, M. B. Honorato, and M. De Araújo Novaesa, "Prototype of care application for obstetric telemonitoring of hypertensive syndromes in high risk pregnancy", in Studies in Health Technology and Informatics, 264, 1769-1770, 2019. https://doi.org/10.3233/SHTI190639 
[11] S. Patel, "Behavioural study of memory allocators for Android platform", in 2017 IEEE International Conference on Consumer Electronics-Asia, ICCEAsia 2017, 2018-January, 52-55, 2018. https://doi.org/10.1109/ICCEASIA.2017.8309320

[12] I. P. G. A. A. Putra, E. Sediyono, and A. Setiawan, "E-land design of mobile application for land information system using Android-based Google Maps API V2", in Proceedings - 2017 International Conference on Innovative and Creative Information Technology: Computational Intelligence and IoT, ICITech, 2018-January, 1-5, 2018. https://doi.org/10.1109/INNOCIT.2017.8319145

[13] K. Yue, L. Jiang, L. Yang, and H. Pang, "Research of embedded database SQLite application in intelligent remote monitoring system", in Proceedings - 2010 International Forum on Information Technology and Applications, IFITA, 2, 96-100, 2010. https://doi.org/10.1109/IFITA.2010.241

[14] R. V. Golhar, P. A. Vyawahare, P. H. Borghare, and A. Manusmare, "Design and implementation of android base mobile app for an institute", in International Conference on Electrical, Electronics, and Optimization Techniques, ICEEOT 2016, 3660-3663, 2016. https://doi.org/10.1109/ICEEOT.2016.7755391

[15] Z. Jiantao and P. Xuan, "Design and implementation of field staff management system on android mobile", in Proceedings - 3rd International Conference on Instrumentation and Measurement, Computer, Communication and Control, IMCCC 2013, 791-794, 2013. https://doi.org/10.1109/IMCCC.2013.176

[16] C. Doukas, T. Pliakas, and I. Maglogiannis, "Mobile healthcare information management utilizing Cloud Computing and Android OS", in 2010 Annual International Conference of the IEEE Engineering in Medicine and Biology Society, EMBC'10, $1037-1040, \quad 2010$. https://doi.org/10.1109/IEMBS.2010.5628061

[17] A. Delgado, D. Vriclizar and E. Medina, "Artificial intelligence model based on grey systems to assess water quality from Santa river watershed," Proceedings of the 2017 Electronic Congress, E-CON UNI 2017, January, 14, 2018.

[18] K. Kalimullah and D. Sushmitha, "Influence of Design Elements in Mobile Applications on User Experience of Elderly People", in Procedia Computer Science, 113, 352-359, 2017. https://doi.org/10.1016/j.procs.2017.08.344

[19] E. Canbazoglu, Y. B. Salman, M. E. Yildirim, B. Merdenyan, and I. F. Ince, "Developing a mobile application to better inform patients and enable effective consultation in implant dentistry", Comput. Struct. Biotechnol. J., 14, 252-261, 2016. https://doi.org/10.1016/j.csbj.2016.06.006

[20] A. Delgado, A. Aguirre, E. Palomino and G. Salazar, "Applying triangular whitenization weight functions to assess water quality of main affluents of Rimac river", Proceedings of the 2017 Electronic Congress, E-CON UNI 2017, January, 1-4, 2018. 